\title{
International Unions
}

\section{Citation}

Alesina, Alberto, Ignazio Ageloni, and Federico Etro. 2005. International unions. American Economic Review 95(3): 602-615.

\section{Published Version}

http://dx.doi.org/10.1257/0002828054201279

\section{Permanent link}

http://nrs.harvard.edu/urn-3:HUL.InstRepos:4553008

\section{Terms of Use}

This article was downloaded from Harvard University's DASH repository, and is made available under the terms and conditions applicable to Other Posted Material, as set forth at http:// nrs.harvard.edu/urn-3:HUL.InstRepos:dash.current.terms-of-use\#LAA

\section{Share Your Story}

The Harvard community has made this article openly available.

Please share how this access benefits you. Submit a story.

Accessibility 

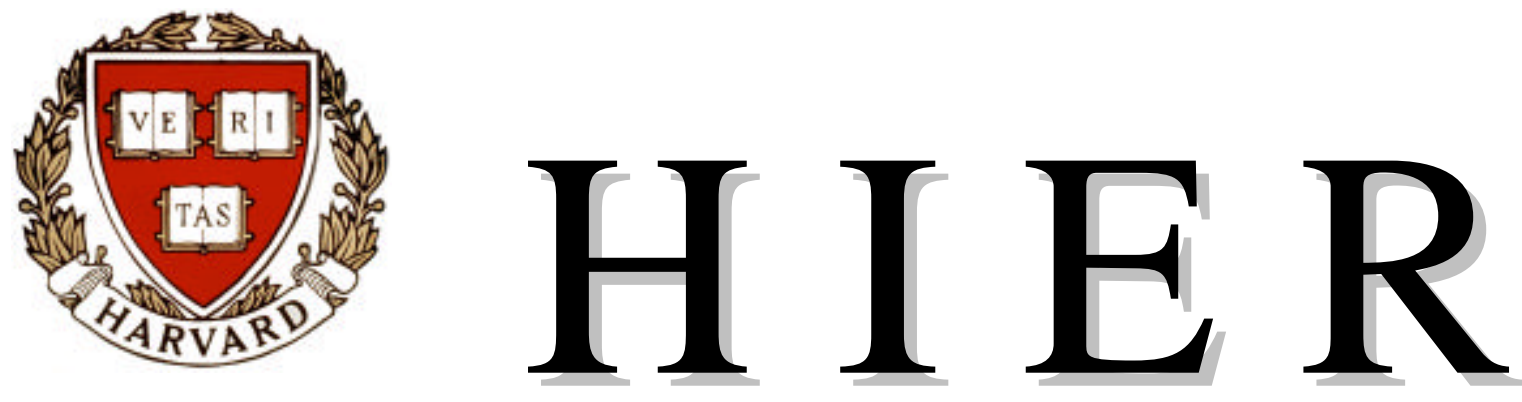

\section{Harvard Institute of Economic Research}

Discussion Paper Number 2001

International Unions

By

Alberto Alesina, Ignazio Angeloni

and

Federico Etro

April 2003

\section{Harvard University Cambridge, Massachusetts}

This paper can be downloaded without charge from:

http://post.economics.harvard.edu/hier/2003papers/2003list.html

The Social Science Research Network Electronic Paper Collection:

http://ssrn.com/abstract=392440 


\title{
International Unions*
}

\author{
by Alberto Alesina*, Ignazio Angeloni** and Federico Etro*** \\ * Harvard University, NBER and CEPR \\ ** European Central Bank \\ *** Ministry of Economy, Italy
}

March 2003

\footnotetext{
*The views expressed in this paper are not necessarily shared by the affiliating institutions. We thank Robert Barro, Tim Besley, Massimo Bordignon, Karina Firme, Roger Gordon, Greg Mankiw, David Laibson, Antonio Rangel, Dany Rodrick, Andres Velasco, two anonymous referees and participants in seminars at the Center for Financial Studies, University of Frankfurt, Catholic University of Milan, Harvard-M.I.T., New York University, NBER and the Villa Mondragone International Economic Seminar at the University of Rome for useful comments. Alesina gratefully acknowledges financial support from the NSF through the NBER. Etro acknowledges financial support from Fondazione Luigi Einaudi. Email correspondence: aalesina@harvard.edu, ignazio.angeloni@ecb.int, fetro@nber.org.
} 


\title{
International Unions
}

\begin{abstract}
We model an international union as a group of countries deciding together on the provision of public goods or policies that generate spillovers across members. The trade-off between benefits of coordination and loss of independent policymaking endogenously determines size, composition and scope of the union. Policy uniformity reduces the union's size, may block enlargement processes and induce excessive centralization. We study flexible rules with non-uniform policies that reduce these inefficiencies focusing on arrangements relevant in the context of existing unions or federal states, like enhanced cooperation, subsidiarity, federal mandates and earmarked grants.
\end{abstract}




\section{Introduction}

Historically, the nation state has concentrated most of the authority in every policy domain. In recent decades, however, a more complex picture has begun to emerge, characterized by a demand for more autonomy (if not secession) at a subnational level and, at the same time, creation or strengthening at the supranational level of country unions which assume certain policy prerogatives. World economic integration seems to be responsible for both developments. On the one hand, in an integrated world, subnational jurisdictions can prosper independently because their market is the world ${ }^{1}$. On the other hand, increasing integration leads to more externalities, need for coordination and, in more extreme cases, supranational jurisdictions. Examples of multilateral arrangements of this kind can include world-wide organizations like the United Nations, regional trade agreements, currency unions, military alliances, etc..

A prominent example is the European Union (EU), which, especially after the Maastricht Treaty (1992), has substantially broadened its scope of action to include, besides a common trade policy and a single internal market, a monetary union, tightly co-ordinated fiscal policies and certain aspects of common domestic and external policies. ${ }^{2}$ An important debate is now underway on what the functions of the EU should be, and where the boundaries between the union's prerogatives and those of member nations should be placed. This debate is spurred in particular by the ongoing preparation of a European Constitution and by the prospective entry in the EU of a long list of applicants, mainly from central and eastern Europe. Several observers (including Alesina, Angeloni and Etro, 2001a, henceforth AAE) have pointed out that there are inconsistencies between the deepening of the scope of the European Union and its enlargement. ${ }^{3}$

This paper examines the political economy of international unions of coun-

\footnotetext{
${ }^{1}$ See Alesina, Spolaore and Wacziarg (2000).

${ }^{2}$ Alesina, Angeloni and Schuknecht (2001) document this trend empirically.

${ }^{3}$ See Alesina and Wacziarg (1999), Tabellini (2002) and Buti, Eijffinger and Franco (2002).
} 
tries. These are groups of countries that coordinate the provision of certain public goods with international spillovers. We examine, in particular, what are the forces that determine the equilibrium size and composition of unions, and discuss the attribution of prerogatives between the union and the member countries. The core of our model, and an element that in our view is central to the political economy of all unions, is the existence of a tension between the heterogeneity of individual countries' preferences and the advantage of taking certain decision in common. ${ }^{4}$

Our paper is related to two different strands of literature. First, the literature on fiscal federalism, which goes back to Oates (1972), takes the size of a union as given and assumes a uniform policy across countries - a feature that characterizes what we call a "rigid union". Recent contributions by Besley and Coate (2003) and Lockwood (2002) have started to explore alternative arrangements that do not impose policy uniformity, taking the size of the union as given. ${ }^{5}$ A second strand of the literature discusses the endogenous determination of the size of the union, assuming policy uniformity. Work along this line includes Alesina and Grilli (1993) and Alesina and Barro (2002) on monetary unions and Yi (1996) on custom unions.

In this paper we make some progress in merging these two literatures. We proceed in two steps. First, we consider a rigid union and show that it generates other inefficiencies beyond the lack of adaptability to local preferences pointed out by Oates (1972). There is first a tendency towards a reduction in the equilibrium size of the union and hence of the externalities associated with it ("small size bias") ${ }^{6}$. Moreover, the political structure can prevent potentially

\footnotetext{
${ }^{4}$ For an historical analysis of union formation close to the spirit of our approach from a political science point of view see Rector (2002).

${ }^{5}$ The focus is on legislative bargaining between countries and strategic delegation. See also the comparisons between centralization and decentralization by Dur and Roelfsema (2002) and Gradstein (2002) on public good provision, Etro and Giarda (2002) on redistributive policy and Persson and Tabellini (1996a,b) on risk sharing in a federation.

${ }^{6}$ Alesina and Spolaore (1997) have emphasized a related tendency toward suboptimal size
} 
efficient enlargements because of a form of "status quo bias". Finally, without a constitutional commitment to centralize only certain policies, a bias toward excessive centralization emerges ("centralization bias"), also leading to small size. There is a time-inconsistency problem here: once the union is formed, a majority of members will want to increase policy prerogatives, and the expectation of this induces many countries to step back from the beginning. Our second step is to remove the assumption of policy uniformity and study simple rules that add flexibility and improve the allocation of resources. Our analysis focuses on arrangements which are central in the debate on the institutional design of the European Union or, more generally, that are relevant in the context of existing federal structures, like enhanced cooperation, subsidiarity, federal mandates and earmarked grants. We show under which conditions these institutions help limiting the inefficiencies of a rigid union.

The paper is organized as follows. Section 2 describes the basic model. Section 3 characterizes the equilibrium size of rigid unions and discusses issues of enlargement and the trade-off between the centralization and the size of the union. Section 4 discusses flexible unions, removing the assumption that every member of the union has to adopt the same policy. Section 5 concludes and indicates some avenues for further research. All proofs are in the Appendix.

\section{The Model}

Consider a group of equally sized countries with equal economic fundamentals and preferences within each country, while preferences differ across countries.

of countries. The two results have however different motivations. The size of countries in their model depends on a trade-off between scale economies and cost of citizens' distance from an exogenous public good, while the size of unions depends on a trade-off between the benefits of policy coordination and the cost of a rigid but endogenous policymaking at the union level. Small countries are a consequence of secessions approved by majority voting within countries, while small unions are a consequence of the loss of independent provision of national public goods. 
Assuming exogenous income $y$ and lump sum taxes financing national public spending $g_{i}$, the utility function for the representative individual of an independent country $i$ is:

$$
U_{i}=y-g_{i}+\alpha_{i} H\left(g_{i}\right)
$$

which is linear in private consumption for simplicity and where $H_{g}(\cdot)>0$ and $H_{g g}(\cdot)<0$. The parameters $\alpha_{i}>0$ capture how much the representative individual of country $i$ values public consumption relative to private consumption: we assume that they are observable and, without loss of generality, that countries are ordered such that $\alpha_{1} \leq \alpha_{2} \leq \ldots{ }^{7}$

If $N$ countries form a union, they enjoy spillovers from each other public spending. The parameter $\beta \in[0,1]$ captures the spillover effects of public spending in other countries. The representative individual in member country $i$ has the following utility function:

$$
U_{i}=y-g_{i}+\alpha_{i} H\left(g_{i}+\beta \sum_{j=1, j \neq i}^{N} g_{j}\right)
$$

Notice that we assume that membership in the union is a necessary condition for receiving some externalities. Spillovers are zero if a country is out. This is a simplifying assumption that could be relaxed without essential changes in the results. ${ }^{8}$ We interpret $g_{i}$ as a public good, such as infrastructures, public

\footnotetext{
${ }^{7}$ We could employ heterogeneity in economic fundamentals (income or productivity) and distortionary taxation obtaining similar results. For models of union formation of this kind see Bolton and Roland (1997), AAE (2001a) and Etro and Giarda (2002).

${ }^{8}$ It is realistic to assume no spillovers between union members and outsiders in the case of a pure public good: union members jointly produce the public good, outsiders do it separately without interdependence. Etro (2002) extends the model allowing the outsiders to be affected by the externalities of the union and viceversa. There, it is shown that whenever strategic sustituibility between the policies of the countries holds, as it does here, free riding by outsiders is increased when a union is created. This reduces the equilibrium size of unions even beyond the suboptimal size emphasized in our paper.
} 
investment or defense. Some of our results would also apply to other forms of international cooperation, such common domestic and external policies, trade agreements or currency unions. The central idea is that the union improves the coordination of some policy with international spillovers.

In a decentralized equilibrium, in which every country acts independently, the provision of public goods would be sub-optimal because of a well known free-riding problem. The first best utilitarian union includes all countries and satisfies the following optimality conditions for each country $i$ :

$$
\alpha_{i} H_{g}\left(g_{i}+\beta \sum_{j \neq i} g_{j}\right)=1-\beta \sum_{j \neq i} \alpha_{j} H_{g}\left(g_{j}+\beta \sum_{k \neq j} g_{k}\right)
$$

This requires that the union dictates a different policy for each country and that the policy preferences of every country are known and verifiable. This seems highly unrealistic especially if information about countries' preferences are not verifiable.

The simplest assumption about the feasible set of policies of the union, following the standard theory of fiscal federalism (Oates, 1972), is that the union is "rigid" namely every member of the union has to adopt the same policy. In this case in order to find the equilibrium policy one has to impose a voting rule. We consider the one-country-one-vote case with majority voting; we briefly discuss qualified majorities below. ${ }^{9}$ Given the structure of preferences, the median voter theorem applies and the level of spending chosen by the $N$ sized union solves the following first order condition:

$$
\alpha_{m} H_{g}\left\{g_{m}[1+\beta(N-1)]\right\}=\frac{1}{1+\beta(N-1)}
$$

which defines a function $g_{m}=g\left(\alpha_{m}, N\right)$ where $\alpha_{m}$ is the preference parameter of the median country in the union. In the following proposition we refer to

\footnotetext{
${ }^{9}$ Note that this is reasonable since all countries have equal size. In many unions, including the EU voting rights are proportional to the population size of the country.
} 
$\theta(g) \equiv-H_{g g}(g) g / H_{g}(g)$ as the elasticity of the marginal utility of public goods (the lower is this, the more highly substitutable are private and public spending):

Proposition 1. In a rigid union, the political equilibrium provision of public goods increases in $\alpha_{m}$ and it decreases (increases) with the size of the union and of the spillovers if the elasticity of the marginal utility of public goods is higher (lower) than unity, while, under unitary elasticity we have size-independence.

The ambiguous effect of an increase in spillovers on the union policy is due to the usual substitution and income effects. The same argument holds for an increase in the number of members. This is relevant for the creation and enlargement of a union. For instance, even if a new country is strictly in favor of a small government and it will increase votes in this direction inside the union, its entry could end up determining a bigger size government: this can happen if the concavity of the function $H(\cdot)$ is not too strong. The intuition is that in this case the substitution effect (more public goods because they produce more spillovers) more than compensates the income effect (more consumption because we have already a lot of spillovers).

\section{Rigid Unions}

In this section we characterize the properties of a "rigid union", defined as one in which all members have to follow the same policy if in the union. First we analyze what we could call an "initial stage" of union formation in which some potential members can unilaterally join the union (an "open rule" process). We then analyze the case in which existing union members have to approve new entrants. ${ }^{10}$ Finally we examine multiple policies (the production of mul-

\footnotetext{
${ }^{10} \mathrm{An}$ interesting extension would be to introduce uncertainty on the benefits from membership, solved after entry, and strictly positive costs of exit. In such an environment, the renegotiation-proof equilibrium would be affected by these costs and may imply a multiple speed entry in the union. See Bordignon and Brusco (2001) for a related analysis on secession
} 
tiple public goods in our model) to examine the relationship between the size and the scope of unions. In these three steps we emphasize three inefficiencies characterizing rigid unions.

\subsection{The equilibrium size of the union}

Consider $M$ potential members of a union, where $M$ is defined as the set of countries that would join a first best union under the provisions of public goods described by the optimality condition (3). Let us define a rigid union $\left(\alpha_{m}, N\right)$ as a group of $N$ countries with median $\alpha_{m}$. The utility of country $i$ in a union $\left(\alpha_{m}, N\right)$, is:

$$
V_{i}^{i n}\left(\alpha_{m}, N\right) \equiv y-g_{m}\left(\alpha_{m}, N\right)+\alpha_{i} H\left\{g_{m}\left(\alpha_{m}, N\right)[1+\beta(N-1)]\right\}
$$

Clearly the utility of a country outside this union is $V_{i}^{\text {out }}=V_{i}^{\text {in }}\left(\alpha_{i}, 1\right)$.

In order to examine the size and the composition of the rigid union we need to address questions of multiplicity of equilibria. Even for a given median country, a simple Nash equilibrium concept would produce multiplicity of equilibria. To see the problem consider entries on both sides of the median which enlarge the union without changing the median itself. In fact no country may want to join a small union but because of strategic complementaries in the entry process a group of countries may find in everybody's interest to join. These different size unions with the same median could be Nash equilibria. To avoid this multiplicity of equilibria, we focus on unions with a given median and adopt a coalition-proof equilibrium concept under which not only unilateral deviations, but all multilateral deviations (which are internally consistent) have to be non profitable. To formalize this concept we need to define $\alpha^{\prime}\left(\Gamma, \alpha_{m}, N\right)$ as the new median of the union $\left(\alpha_{m}, N\right)$ after a set $\Gamma(S)$ of $S$ previously outsider countries joins to it.

rules. 
An equilibrium union $\left(\alpha_{m}, N\right)^{E}$ is a group of $N$ countries with a median voter characterized by $\alpha_{m}$, such that:

1) the union policy is chosen by the union by majority voting,

2) for each country $i$ joining the union, $V_{i}^{\text {in }}\left(\alpha_{m}, N\right)>V_{i}^{\text {out }}$, and

3) in the set of the countries outside the union, there is not a subset of $S$ countries $\Gamma(S)$ such that:

$$
V_{k}^{\text {in }}\left(\alpha^{\prime}\left(\Gamma, \alpha_{m}, N\right), N+S\right)>V_{k}^{\text {out }} \quad \forall k \in \Gamma(S)
$$

Under this definition there may still be multiple equilibria with different median countries, ${ }^{11}$ hence, for simplicity we are going to focus on the properties of a single equilibrium union with a given median country. In other words we do not study the optimal number of union for given configuration of countries in the world, a question which would lead us closer to the work of Alesina and Spolaore (1997) and Alesina and Barro (2002). In all the following results we do not impose any structure on the distribution of the preferences except for a strictly technical one which limits the heterogeneity between countries: given $\alpha_{i} \in$ $\left[\alpha_{\min }, \alpha_{\max }\right]$ for any $i$, we will assume $\alpha_{\max }<2 \alpha_{\min }$. Finally we set a limit on the concavity of the utility function: $\theta(g) \geq 1 / 2$. These assumptions are sufficient but not necessary for our conclusions. If they do not hold we cannot exclude "perverse" cases in which groups of countries with very different preferences form multiple unions excluding countries with intermediate preferences. For more details on this technical point see AAE (2001a). Under these assumptions we have:

Proposition 2. An equilibrium union is composed by countries with contiguous preferences: for a given median, there exists a unique compact set of preferences around it, such that all and only all countries with preferences in

\footnotetext{
${ }^{11}$ Allowing coalitions between union members and outsiders would reduce further this multiplicity of equilibria, but such an analysis is beyond the scope of this paper.
} 
this set belong to the union; the equilibrium size of the union is (weakly) increasing in the size of the spillovers.

The point of this proposition is that the equilibrium is formed by countries with similar preferences who gain in the trade-off between the benefits from cooperation and the costs from the loss of independent policymaking. ${ }^{12}$ When the size of the spillovers decreases - or the heterogeneity of preferences increases - the equilibrium size of the union shrinks and for low enough spillovers or great enough heterogeneity, $N<M$. As well known since Oates (1972), centralization in a rigid union has the benefit to internalize spillovers in policymaking and the cost of giving up to adaptability to local preferences. Our point is that there is a further cost from centralization in unions of independent countries: the rigidity of central policymaking reduces the size of the union below the optimal one, which is $M$ in our case, and hence it reduces the total spillovers. We may call this a "small size bias" of rigid unions. ${ }^{13}$

\subsection{Enlargement}

We now examine the issue of union enlargement. First of all notice that if two new candidate countries on opposite sides of the median are considered, under our assumptions they will unambiguously raise the utility of all the current

\footnotetext{
${ }^{12}$ This trade off is at the basis of related investigations on the endogenous creation of unions. Wrede (2002) and Cernaglia (2002) extend our model introducing retrospective voting on the politicians in the former and legislative bargaining in the latter. Brou and Ruta (2002) and Cheikbossian (2002) extend our model to examine the role of special interest politics and rent-seeking activities. Perotti (2001) and Facchini (2002) study the political economy of a common market.

${ }^{13}$ Even mantaining the uniform policy assumption of the rigid union, there are partial solutions to this inefficiency. One would be a system of side payments toward countries with extreme preferences to induce them to join the union. To some extent these transfers would be selfinanced through the new spillovers created. Another partial solution would be the adoption of a system of legislative bargaining where the agenda setter chooses a policy and a size of the union under the constraint that all its members are better off inside the union.
} 
members and so they will all be admitted. This implies that the interesting problem is the admission of a single country. We will study under which conditions such an enlargement takes place as a single event. However, an important paper by Roberts (1999) has studied a general model of dynamic enlargement of a union. In such a model, the entry of a new member changes the median and subsequent decisions about policy and further enlargement will be taken by a different set of countries; nevertheless, Roberts has shown that a median voter theorem holds also in such a model even if its steady states may not be political equilibria of the static game. Our model is a particular case of what he calls "expansionary clubs" and his results apply to it. ${ }^{14}$ Our analysis will differ because we will just analyze the candidacy of a single country. Anyway, our results should be seen as complementary to Roberts' ones in showing the existence of a "status quo bias" in the enlargement processes: enlargement and creation of new spillovers may be opposed (or postponed) by members of the union who do not want to give up to their political power in the union.

Let us begin with the case in which a simple majority of members is needed to admit a new entrant. Its potential entry has two effects. The first is to increase utility by virtue of the internalized externality, the second is to change the median voter in the union: a majority of the members must enjoy a positive net gain from these effect. Moreover, there cannot be an admission with contemporaneous exit of a previous member: otherwise spillovers would not increase, but the median would change, making impossible a majority in favor of the entrant. These two constraints motivate the following:

Proposition 3. An equilibrium union will always accept by majority voting two new members on opposite sides of the median and will accept by majority

\footnotetext{
${ }^{14}$ The only difference is that Roberts considers expansion only in one direction of the preference parameter. However, in a dynamic version of our model all the couple of countries on the opposite side of the median and closer to it would be immediately admitted: afterwards the dynamic would be the same predicted by the Roberts' model.
} 
voting a single new member if and only if the change in the median after entry is small enough.

Thus, just countries close enough to the current median of the union are accepted. Hence our model rationalizes a form of status-quo bias in union reforms: informally, it is inefficient to give up to new spillovers for political reasons. Note that the spirit of our result goes through if the admission of more countries together is allowed and all these countries are on the same side of the median. Clearly a partial solution would be an admission without voting power, which would allow any country to be admitted. This is what recently happened when Russia joined the NATO, but it is hard to imagine such a solution in the European Union.

\subsection{Qualified majorities}

In many unions (including the EU) admission of new members requires much more stringent procedures, like qualified majority or even unanimity. ${ }^{15}$ In these cases the status quo bias is just reinforced. Consider unanimity for instance. The pivotal country is that with the preferences furthest away on the opposite side of the median with respect to the candidate country. This pivotal country will compare the change of its utility due to the increase in externalities with that coming from the policy change due to the new median and vote accordingly. This country will block the new entrant if its utility decreases. Note that under majority voting we had to make sure that this same country was not exiting the union; that is we needed that its utility remained above the reservation utility of being out even though it might decrease due to the new entrant. With unanimity we have to make sure that this country is actually (weakly) better off after the enlargement, which is a more stringent requirement. More generally, in any case of qualified majority voting, the set of admissible entrants is smaller

\footnotetext{
${ }^{15}$ For a discussion of qualified majority procedure also in the choice on the provision of public goods see AAE (2001b).
} 
than in the case of majority voting and what we called the status quo bias of the union is larger.

\subsection{Size and scope of the union}

We now extend the simple policy model of the union to multiple policies. Imagine $F$ different types of public goods, ordered by the intensity of spillovers, $\beta_{1}>\beta_{2}>\cdots>\beta_{F}$. Assuming separability between subutilities, the utility function is now: ${ }^{16}$

$$
U_{i}=y-\sum_{k=1}^{F} g_{i}^{k}+\alpha_{i} \sum_{k=1}^{F} H\left[g_{i}^{k}+\sum_{j \neq i} \beta_{k} g_{j}^{k}\right]
$$

Let us define with $V_{i}^{G}\left(\alpha_{m}, N\right)$ the utility of country $i$ joining a union of $N$ members with median $\alpha_{m}$ and producing the set of public goods $G$ - for instance, if $F=2, G$ may be $(1,2)$ or (1) or (2)-, and with $V_{i}^{\text {out }}=V_{i}^{G}\left(\alpha_{i}, 1\right)$ the utility from the decentralized production of the same set of goods. According to the voting procedure in the union, different results may arise. The common and realistic assumption is that only after the creation of the union, its members, which are committed to be in it, decide on policymaking in the union, while the outsiders choose independently on all their policies. We will discuss two different kinds of equilibria, characterized by the following alternative voting rules within the union:

RULE A. The provisions of each public good are chosen sequentially by majority voting.

RULE B. The policies to centralize are chosen by majority voting and, subsequently, for each centralized policy, the provisions of each public good are chosen sequentially by majority voting.

\footnotetext{
${ }^{16}$ Our result would not change qualitatively if the distribution of preferences, as reasonable, was different across policies (in that case the median country would differ between different policies).
} 
The difference between rule $\mathrm{A}$ and $\mathrm{B}$ is that the latter allows a two step decision: first which policy to centralize, and then how much of each public good to provide. Notice that there is just a difference in procedures, not in what is the feasible set of options.

$A X$-equilibrium union $\left(\alpha_{m}, N, G\right)^{E}$ is a group of $N$ countries with a median voter characterized by $\alpha_{m}$, providing a set of public goods $G$, such that:

1) rule $X \in(A, B)$ applies;

2) for each country $i$ joining the union, $V_{i}^{G}\left(\alpha_{m}, N\right)>V_{i}^{\text {out }}$, and

3) in the set of the countries outside the union there is not a subset of $S$ members $\Gamma(S)$ such that:

$$
V_{k}^{G}\left(\alpha^{\prime}\left(\Gamma, \alpha_{m}, N\right), N+S\right)>V_{k}^{\text {out }} \quad \forall k \in \Gamma(S)
$$

Note that the first stage of voting with Rule B (i.e. which policies to centralize) may appear multidimensional leading to Condorcet cycles. However given the structure of the model the voting space can be reduced to a unidimensional space. In fact everybody agrees that if $\mathrm{K}$ policies have to be centralized it will be the $\mathrm{K}$ policies with the highest spillovers. In other words, issue-by-issue voting and separable preference guarantee the existence of a single Condorcet winner at each voting stage. In Appendix we prove existence and uniqueness of equilibrium under both rules and:

Proposition 4. An equilibrium union is composed by countries with contiguous preferences and for a given median, rule B implies a (weakly) greater size and a (weakly) smaller set of centralized policies than rule $A$ and it is preferred by at least a majority of countries.

If Rule A is adopted, all policies are centralized obtaining a relatively "small" but highly centralized union. An interesting feature of this equilibrium is that it is possible that a majority of members would prefer to centralize only the policies with higher spillovers, even though, in an A-equilibrium this does not happen. 
More in general, Rule A generates a size of the union (weakly) smaller than the one obtained under Rule B which is also (weakly) smaller than the optimal one (again the full set of potential members): hence we have a further form of inefficiency under Rule A, whose source is the centralization of all policies. ${ }^{17}$ Unfortunately, this "centralization bias" in the union is quite pervasive, since it is due to a time-inconsistency problem: once the union is formed, the median extends excessively its powers, and the expectation of this induces too many countries to step back from the beginning.

The intuition for the equilibrium outcome under rule B is the following. Member countries rationally foresee the provision of public goods chosen by the median for each centralized policy and this makes the extreme countries worse off when the number of centralized policies increases. For this reason extreme countries ( on both sides of the median, i.e. both those countries that would find the median provision of certain policies to low or to high) vote for the centralization of only few policies while the median country votes for the centralization of all policies. Hence, the median number of centralized policies is typically lower than $F$ as long as heterogeneity within the union is great enough. Given this, some extreme countries may still choose not to join the union in the initial stage, but membership must be at least as great as under rule A, since the latter implies centralization of all policies.

In other words, we have shown that a strong commitment of the union to centralize only a limited set of policies - those with the strongest spillovers between members - can induce the creation of a bigger union and is preferred by at least a majority of members. Our results suggest that there are benefits for the forthcoming European Constitution to set clear limits on which policy prerogatives belong to the EU. This is indeed one of the most debated issues in

\footnotetext{
${ }^{17}$ Despite general welfare comparisons are impossible, it is easy to build examples in which rule $\mathrm{B}$ strictly dominates rule $\mathrm{A}$, that is, its adoption makes all countries at least as well off and at least one of them strictly better off (because of the increase in the size and in the spillovers), while the opposite can never be true.
} 
the Constitutional Convention.

\section{Flexible Unions}

In the previous section we have shown the existence of three forms of inefficiency in the creation of a rigid union: policy uniformity reduces memberships and hence the associated spillovers; a status quo bias limits enlargement, especially when candidate countries differ from the incumbents and when super-majorities are required for admitting new members; in the absence of a commitment to limited delegation of powers to the union, there is excessive centralization leading to reduction in the size of the union.

This section will study four forms of flexible unions, i.e. unions where policies differ among members, which reduce these inefficiencies. We know that optimality requires different policies for different members. However implementation of the first best raises two sets of problems. First, the organizational costs of discriminating policy across the membership could be very large. This could perhaps be modelled by adding a variable cost, increasing with the complexity (in terms of differences in policies). Second, and perhaps more importantly, to the extent that preferences are not verifiable, countries would have an incentive to declare and act upon preferences different from their own. It is therefore instructive to check how various "simple" arrangements - based on simple rules applying equally to all countries - can improve upon the rigid union without requiring the institutional complexity of the first best arrangement.

\subsection{Enhanced cooperation}

Under this arrangement, subsets of union members are free to centralize certain policies among themselves, without the other members of the union participating. Allowing certain countries to centralize some policies at the union level and other countries to centralize other policies reduces the centralization bias em- 
phasized in the previous section. Indeed, in a multiple policies model, enhanced cooperation corresponds to the formation of many unions, whose size is (weakly) increasing in the spillovers associated with the policy.

This arrangement is a reality in the EU, where for example just some members have adopted the single currency or agreed on common border controls. The Amsterdam Treaty (1997) has introduced a formal framework for forms of enhanced cooperation, whereby any group of (at least eight) members to take action in particular areas, while other members opt out. ${ }^{18}$ This arrangement clearly (at least weakly) increases the size of the union which is now the set of countries willing to centralize the policy with highest spillovers. This institutional design is favored by countries with very different preferences from the median country and it encourages enlargement, but countries close to the median may prefer rules like rule A and B of the previous section which imply higher centralization and smaller participation. The advantage of this form of flexibility would be enhanced if both preferences and spillovers are heterogeneous, but presumably, implementation costs may become very large if this is pushed toward an extreme diversification. For further details see AAE (2001a).

\subsection{Subsidiarity}

We now analyze another form of flexibility, the principle of subsidiarity. This corresponds to a well known feature of the European Union, laid out in Article 3b of the Maastricht Treaty (1992), that states that "In areas which do not fall within its exclusive competence, the Community shall take action, in accordance with the principle of subsidiarity, only if and in so far as the objectives of the proposed action cannot be sufficiently achieved by the Member States and can therefore, by reason of the scale or effects of the proposed action, be better

\footnotetext{
${ }^{18}$ Bordignon and Brusco (2003) introduce uncertainty on the benefit of coordination in a model of union formation and rationalize enhanced cooperation as an optimal step toward full coordination.
} 
achieved by the Community". In other words, public policies should be assigned to the lowest level of government which is capable of successfully achieving their objectives (see Inman and Rubenfeld, 1998). In our model we have exactly a situation were each member's policy does not internalize the effects on the other members and so it cannot sufficiently achieve its objectives. Hence, the principle of subsidiarity implies that the union should complement countries' expenditure in the public good with an additional expenditure at the union level.

Formally, a union $\left(\alpha_{m}, N\right)$ chooses an expenditure $g_{m}^{U}$ by majority voting (the median voter theorem still holds), while each country $i$ chooses $g_{i}^{n} \in(0, y-$ $\left.g_{m}^{U}\right)$. Utility for country $i$ is now:

$$
U_{i}=y-g_{i}^{n}-g_{m}^{U}+\alpha_{i} H\left[g_{i}^{n}+\beta \sum_{j \neq i} g_{j}^{n}+g_{m}^{U}[1+\beta(N-1)]\right]
$$

The timing assumption in our description of the principle of subsidiarity is that the countries choose their individual public expenditure in a first stage, and the union decides a complementary expenditure in a second stage. In particular, the median country will choose $g_{m}^{U}$ to maximize $U_{m}$. Given the expectation $E\left(g_{m}^{U}\right)$, all the countries in the first stage choose $g_{i}^{n}=g^{n}\left(\alpha_{i}, E\left(g_{m}^{U}\right)\right), i=1,2, \ldots, N$, to maximize $U_{i}$. In equilibrium it must be $E\left(g_{m}^{U}\right)=g_{m}^{U}$. Given this, the sub-game perfect equilibrium is defined by the following system of $N+1$ equations:

$$
\begin{aligned}
& \alpha_{i} H_{g}\left[g_{i}^{n}+\beta \sum_{j \neq i} g_{j}^{n}+g_{m}^{U}[1+\beta(N-1)]\right] \leq \frac{1}{1+[1+\beta(N-1)] \frac{\partial g_{m}^{U}}{\partial g_{i}^{n}}} \\
& g_{i}^{n} \geq 0 \geq i=1,2, \ldots, N \\
& \alpha_{m} H_{g}\left[g_{m}^{n}+\beta \sum_{j \neq m} g_{j}^{n}+g_{m}^{U}[1+\beta(N-1)]\right]=\frac{1}{[1+\beta(N-1)]}
\end{aligned}
$$

Given $\sum_{j \neq m} g_{j}^{n}$ as chosen in the first stage, the last equation defines $g_{m}^{U}=$ $g_{m}^{U}\left(\alpha_{m}, \sum_{j \neq m} g_{j}^{n}\right)$ as a function increasing in the first argument and decreasing 
in the second one with:

$$
\frac{d g_{m}^{U}}{d g_{i}^{n}}=-\frac{\beta}{[1+\beta(N-1)]}
$$

Substituting this in (10) we obtain that for all countries individually providing additional public goods:

$$
\alpha_{i} H_{g}\left[g_{i}^{n}+\beta \sum_{j \neq i} g_{j}^{n}+g_{m}^{U}[1+\beta(N-1)]\right]=\frac{1}{1-\beta}
$$

Hence, we have shown that $g_{m}^{U}\left(\alpha_{m}, \sum g_{j}^{n}\right) \leq g_{m}^{U}\left(\alpha_{m}, 0\right)$ and that $\alpha_{i} H_{g}(\cdot)<1$ for any $i \leq m$. We prove:

Proposition 5. With subsidiarity 1) the expenditure of the union is lower than the one adopted by a rigid union, 2) the median country and all countries with weaker preferences for the public good do not add any individual expenditure and 3) the countries with strongest preferences for the public good add individual expenditure. In a rigid union with a given median, the adoption of a complementary structure is Pareto-efficient and (weakly) enlarges the union.

The outcome is a compromise between the decentralized one and the rigid one. Countries with lower $\alpha$ will spend less then in a rigid union, while benefiting from the additional expenditure of countries with opposite preferences: hence they are better off. The median country must be better off because it is always able to replicate the public expenditure of the rigid system (with the opportunity to be better off if some countries provide further expenditure). Hence a strict majority is in favor of the flexible system. The other countries on the one hand are worse off because the union is providing less public good, and on the other hand they are better off because to some extent they can individually repair to this. It turns out that the second effect is always prevailing. Notice that while the union expenditure is chosen internalizing the externalities across countries as in the rigid union, the free riding of the single countries is enhanced: even for those countries which add individual expenditure, the private cost of it is 
not 1 as in a decentralized setting, but $1 /(1-\beta)>1$ which is increasing in the spillovers. The status quo bias of the rigid union is limited under subsidiarity: for instance, it is much easier to admit countries with preferences for higher public spending than the median, since beyond changing the median, they are going to provide extra public goods.

\subsection{Federal mandates}

An alternative arrangement that we analyze in this section is the "federal mandate": each country can choose and independently finance public expenditure, but this must be at least equal to a level decided at the union level. Hence each country chooses an individual provision on top of the one decided by the federation. We can think of the situation in which the union moves first and the country later on as a description of federal mandates. ${ }^{19}$ In this context the subgame-perfect equilibrium is characterized by the system:

$$
\begin{aligned}
\alpha_{i} H_{g}\left[g_{i}^{n}+\beta \sum_{j \neq i} g_{j}^{n}+g_{m}^{U}[1+\beta(N-1)]\right] & =1 \text { for } i=N-\tilde{N}, \ldots, N \\
g_{i}^{n} & =0 \text { for } i=1,2, \ldots, m, \ldots, N-\tilde{N} \\
\alpha_{m} H_{g}\left[\beta \sum_{j \neq m} g_{j}^{n}+g_{m}^{U}[1+\beta(N-1)]\right] & =\frac{[1+\beta(\tilde{N}-1)]}{[1+\beta(N-1)](1-\beta)}
\end{aligned}
$$

so that $\tilde{N}$ countries add individual public expenditure to the amount $g_{m}^{U}$ decided as the federal mandate. As long as $\tilde{N} \geq 1$ a free riding behavior on the part of the same union emerges: for the union, the marginal cost of public spending is greater than 1, which remains the marginal cost of each single country as in the decentralized setting, but it is smaller than the one of a rigid union. This

\footnotetext{
${ }^{19}$ Cremer and Palfrey (2000) have studied this kind of federal mandates, however in their model there are not externalities between countries. In our model, instead, the federal mandate accomplishes an important role: it limits the free-riding of the decentralized equilibrium internalizing to some extent the externalities produced in public good provision.
} 
further free-riding of the union may induce some countries after the median to prefer a rigid union. However we can show:

Proposition 6. The adoption of a federal mandate implies that 1) the federal mandate is lower than the public expenditure adopted by the rigid union, 2) the median country and all countries with weaker preferences for the public good do not add any individual expenditure and 3) the countries with strongest preference for the public good add individual expenditure. As long as total spending increases, the adoption of a federal mandate is Pareto-efficient and (weakly) enlarges the union.

\subsection{Earmarked grants}

We now study a simple system of taxes and subsidies which is inspired by widespread forms of intergovernmental transfers usually referred to as earmarked grants (as opposed to block grants, whose purpose is purely redistributive). An example is in the way the European Union creates incentives for regional investment through Structural Funds. Certain kinds of investment, especially those located in poorer regions, aimed at their development or to environmental protection and characterized by spillovers on the Community, is subsidized by the European Union: for each Euro devoted to it, a supplementary fraction is added by the Union. As we will see, such a system may have positive consequences, up to implementing the first best union, but even negative ones, up to inducing the collapse of the union. The result depends on the distribution of preferences across countries.

In AAE (2001b) we study more general tax systems, but here we focus on a constant subsidy $s$ for unit of national expenditure, financed with taxes $T_{i}=s \bar{g}_{-i}$, where $\bar{g}_{-i}$ is the average of all other countries expenditures: hence the tax paid by country $i$ is independent from its choice of spending and the union budget constraint is always satisfied. We can write the problem of each 
country $i$ as the choice of $g_{i}$ to maximize:

$$
U_{i}=y-g_{i}-T_{i}+\alpha_{i} H\left[g_{i}(1+s)+\beta \sum_{j \neq i} g_{j}(1+s)\right]
$$

The choice of each country generates spending $g_{i}=g_{i}(s)$ which is increasing (constant) in the subsidy if and only if $\theta<(=) 1$. Hence indirect utility for country $i$ is:

$$
V_{i} \equiv y-g_{i}(s)-s \frac{\sum_{j \neq i} g_{j}(s)}{N-1}+\alpha_{i} H\left\{(1+s)\left[g_{i}(s)+\beta \sum_{j \neq i} g_{j}(s)\right]\right\}
$$

Maximizing this with respect to the subsidy provides the optimal subsidy for country $i$. It turns out that under weak conditions, we have an interior equilibrium which is increasing in $\alpha_{i}$, hence the median voter theorem holds, and the political equilibrium subsidy $s_{m}$ satisfies:

$$
\left[\frac{N-1}{1+s_{m}}\right]\left[\frac{g_{m}\left(s_{m}\right)}{\bar{g}_{-m}}+\beta(N-1)-\left(1+s_{m}\right)\right]=\left[s_{m}-\beta(N-1)\right]\left[\sum_{j \neq m} g_{j}^{\prime}\left(s_{m}\right)\right]
$$

In this formula, the left hand side represents the direct effect of a change in the subsidy and it is evaluated according to the preference for public spending of the median country compared to the average one. The right hand side is the indirect effect due to the impact on public spending in other countries: when the subsidy is low (which implies underspending), the indirect marginal effect of an increase in the subsidy is beneficial only if it increases spending by the other countries (if $\theta<1$ ). As we will prove, the subsidy $s^{*}=\beta(N-1)$ delivers the first best allocation of public expenditure. The intuition for this is quite simple. The additional expenditure in the public good which is provided by the union distorts the incentives to invest in the public good. These incentives are the same for every country as in the first best if the marginal cost of public 
expenditure equates its social marginal cost. But this is the same for every country and given by $1 /[1+\beta(N-1)]$, hence this equality is satisfied under the proposed subsidy. Now, it is immediate to verify from (17) that if $\theta>1$, we have a subsidy above the optimal one whenever median public spending is more than average, while if $\theta<1$, we have a subsidy below the optimal one whenever median public spending is less than average. In the simple case of logarithmic preferences we have $s_{m}=s^{*}+\left(g_{m}-\bar{g}_{-m}\right) / \bar{g}_{-m} \cdot{ }^{20}$ More importantly we have:

Proposition 7. The adoption of a subsidy to national public expenditure implements the first best allocation of public expenditure if and only if median public spending is the same as the average. Under this condition there is always a system of transfers that gives rise to the first best union.

Informally, as long as the median country is not excessively biased toward low or high public expenditure compared to the average country, a union close to the first best can be created with a system of taxes and transfers. Unfortunately, this does not need to be the case: the political equilibrium subsidy might be too low (or even negative) to be accepted by countries with high preference for public spending (this is more likely when $\beta$ and $\alpha_{m}$ are small and $\theta$ large) or too high to be accepted by countries with low preferences for public spending. Moreover, AAE (2001b) provide a wide discussion on the many reasons for which such a system may not work in general ${ }^{21}$ and may be hardly implementable in practice. Nevertheless, our result shows that a system of intergovernmental

${ }^{20}$ Under isoelastic preferences, we have:

$$
s_{m}=\frac{\theta\left[s^{*}+\left(g_{m}-\bar{g}_{-m}\right) / \bar{g}_{-m}\right]+(1-\theta) s^{*}\left(1+s^{*}-\beta\right)}{1+\left(s^{*}-\beta\right)(1-\theta)}
$$

\footnotetext{
${ }^{21}$ With more general utility functions the first best would not be attainable with a simple subsidy even without further distorsions. Notice also that if transfers contingent on preferences hose implicitly in Proposition 7) were not allowed, participation to the union by all countries may not be feasible.
} 
transfers could be very useful to enlarge the benefits of policy coordination at least in a union with a balanced distribution of preferences.

\section{Conclusions}

We modelled an international union as a set of heterogeneous countries deciding together on the provision of certain public goods (or policies) that generate externalities across union members. First, we have characterized the equilibrium size of a "rigid" union - one in which the provision of the public good is homogeneous across members - showing that several inefficiencies arise, beyond that emphasized by Oates (1972). Second, we have analyzed some simple forms of "flexibility" that can generate welfare improvements by removing the assumption of uniform provision. Our choice of flexible rules was inspired mainly by the current debate on the institutional architecture of the European Union. We have shown how some forms of flexibility (such as subsidiarity, federal mandates, enhanced cooperation, and earmarked grants) can improve welfare and even, under restrictive conditions, attain the social optimum.

Throughout our analysis we have assumed that the size of the member countries is given and equal, that the benefits from membership are certain and the cost of leaving the union is nil, and that there are no organizational costs in implementing our forms of flexibility. Each of these assumptions is restrictive, and their relaxation would represent useful avenues for further research.

First, one could analyze the relationship between the union and the size if countries, the focus of Alesina and Spolaore (1997). Recent history has been characterized, especially in Europe, by the co-existence of centrifugal forces within nations (pressure towards regional autonomy in most Western European countries and the break-up of some Eastern European nations) and centripetal forces at a supranational level (the tendency to delegate policies to supernational entities like the European Union). These two forces may have a natural 
interconnection: the benefits from participating in international unions may reduce the equilibrium size of nations. Separatism within nations and delegation of policies to supernational entities could well be shown, by future research, to be complementary parts of the same process.

Second, the benefits from membership in a union are often uncertain and the cost of leaving a union are obviously large, as history (where cases of union break-ups are rare) shows. Removing the assumption of no cost under uncertainty on the benefits of membership would change the composition, size and scope of the union and rationalize forms of multiple speed unions or progressive enlargement.

Thirdly, there is obviously a limit to how complex the institutional arrangement of a flexible union can be. Realistic models should incorporate a trade-off between institutional simplicity and the ability of the union to attain good welfare properties by getting closer to the preferences of each member. This element of realism is missing in our models. The history of existing unions should again provide a rich source of inspiration in this respect.

\section{References}

Alesina, Alberto, Ignazio Angeloni and Federico Etro, 2001a, The Political Economy of International Unions, NBER wp N. 8645

Alesina, Alberto, Ignazio Angeloni and Federico Etro, 2001b, Institutional Rules for Federations, NBER wp N. 8646

Alesina, Alberto, Ignazio Angeloni and Ludger Schuknecht, 2001, What Does the European Union Do?, NBER working paper N. 8647

Alesina, Alberto and Robert Barro, 2002, Currency Unions, Quarterly Journal of Economics, 117 (2), 409-36

Alesina Alberto and Vittorio Grilli, 1993, On the feasibility of a One Speed or a Multi Speed European Monetary Union, Economics and Politics, 5: 145-66.

Alesina, Alberto and Enrico Spolaore, 1997, On the Number and Size of Nations, Quarterly Journal of Economics, 112:4, 1027-56 
Alesina, Alberto, Enrico Spolaore and Romain Wacziarg, 2000, Economic Integration and Political Disintegration, The American Economic Review, 90 (5), 1276-97

Alesina, Alberto and Romain Wacziarg, 1999, Is Europe Going too far ?, CarnegieRochester Conferences Series on Public Policy 51, 1-42

Besley, Timothy and Stephen Coate, 2003, Centralized versus Decentralized Provision of Public Goods: A Political Economy Analysis, Journal of Public Economics, forthcoming

Bolton, Patrick and Gerard Roland, 1997, The Break up of Nations: A Political Economy Analysis, Quarterly Journal of Economics, 112 (4), 1057-90

Bordignon, Massimo and Sandro Brusco, 2001, Optimal Secession Rules, European Economic Review, 45, 1811-34

Bordignon, Massimo and Sandro Brusco, 2003, On Enhanced Cooperation, mimeo, NYU

Brou, Daniel and Michele Ruta, 2002, A Positive Explanation of EU Enlargement, mimeo, Columbia University

Buti, Marco, Sylvester Eijffinger and Daniele Franco, 2002, Revisiting the Stability and Growth Pact Design or Internal Adjustment?, CEPR wp 3692

Cernaglia, Floriana, 2002, Distributive Politics and Federations, SIEP, University of Pavia, 120-58

Cheikbossian, Guillaume, 2002, Lobbying and Rent-Seeking for Public Goods in a Fiscally Centralized System, mimeo, Université de Perpignan and GREMAQ, Toulouse

Cremer, Jacques and Thomas Palfrey, 2000, Federal Mandates by Popular Demand, Journal of Political Economy, 108, 905-27

Dur, Robert and Hein Roelfsema, 2002, Why does Centralization Fail to Internalize Policy Externalities?, Tinbergen Institute Discussion Paper 056/3

Etro, Federico, 2002, International Policy Coordination with Economic Unions, Rivista Internazionale di Scienze Sociali, 110 (2), 187-211

Etro, Federico and Piero Giarda, 2002, Redistribution, Decentralization and Constitutional Rules, QIEF 49, UCSC, Milan 
Facchini, Giovanni, 2002, Why join a Common Market? The Political Economy of international Factor Mobility in a Multi-Country setting, mimeo, University of Illinois at Urbana-Champaign

Gradstein, Mark, 2002, The Political Economy of Sustainable Federations, mimeo, Ben Gurion University, Israel

Inman, Robert and Daniel Rubinfeld, 1998, Subsidiarity and the European Union, NBER wp \# 6556

Lockwood, Ben, 2002, Distributive Politics and the Costs of Centralization, Review of Economic Studies, 69 (2), 313-37

Oates, Wallace, 1972, Fiscal Federalism, New York, Harcourt Brace Jovanovich

Perotti, Roberto, 2001, Is a Uniform Social Policy Better? Fiscal Federalism and Factor Mobility, The American Economic Review, 91 (3), 596-610

Persson, Torsten and Guido Tabellini, 1996a, Federal Fiscal Constitutions: Risk Sharing and Redistribution, Journal of Political Economy, 104, 979-1009

Persson, Torsten and Guido Tabellini, 1996b, Federal Fiscal Constitutions: Risk Sharing and Moral Hazard, Econometrica, 64, 623-46

Rector Chad, 2002, Federations in International Politics, PhD Dissertation, University of San Diego

Roberts, Kevin, 1999, Dynamic Voting in Clubs, LSE Sticered dp TE/99/367

Tabellini, Guido, 2001, The Assignment of Tasks in an Evolving European Union, Center for European Policy Studies N.10

Wrede, Matthias, 2002, Small States, Large Unitary States and Federations, CESifo Working Paper \#729

Yi, Sang-Seung, 1996, Endogenous Formation of Customs Unions under Imperfect Competition: Open Regionalism is Good, Journal of International Economics, 41, $153-77$ 


\section{Appendix}

Proof of Proposition 1. By total differentiation of (4) we have:

$$
\frac{d g_{m}}{d \alpha_{m}}=\frac{g_{m}}{\alpha_{m} \theta(\cdot)}>0, \quad \frac{d g_{m}}{d \beta(N-1)}=\frac{g_{m}}{[1+\beta(N-1)]}\left(\frac{1-\theta(\cdot)}{\theta(\cdot)}\right)
$$

which implies the result. Q.E.D.

In order to prove Propositions 2-4 we need to first establish two lemmas:

LEMMA 1. The net gain from participating to a union $\Delta(\alpha, \beta)$ is a concave function in the preference parameter $\alpha$ which has positive value only for a closed set of values of $\alpha$.

For a given union $\left(\alpha_{m}, N\right)$ and spillovers $\beta$, we can define the net utility of staying into it for the country with preferences $\alpha_{i}$ as the function:

$$
\begin{aligned}
\Delta\left(\alpha_{i}, \beta\right) & \equiv V_{i}^{\text {in }}\left(\alpha_{m}, N\right)-V_{i}^{\text {out }}= \\
& =\alpha_{i}\left[H\left\{g_{m}[1+\beta(N-1)]\right\}-H\left(g^{o}\left(\alpha_{i}\right)\right)\right]-\left[g_{m}-g^{o}\left(\alpha_{i}\right)\right]
\end{aligned}
$$

where $g^{o}\left(\alpha_{i}\right) \equiv g\left(\alpha_{i}, 1\right)$ is the independent choice of public provision of country $i$, which satisfies $\alpha_{i} H_{g}\left(g^{o}\right)=1$. Using the envelope theorem we have:

$$
\begin{aligned}
\Delta_{\alpha} & =H\left\{g_{m}[1+\beta(N-1)]\right\}-H\left(g^{o}(\alpha)\right), \\
\Delta_{\alpha \alpha} & =-H_{g}\left(g^{o}(\alpha)\right) g^{o \prime}(\alpha)<0
\end{aligned}
$$

which shows concavity in $\alpha$. Moreover, $\Delta(0, \beta)<0$ and $\Delta_{\alpha}(0, \beta)>0$. This and the fact that $\Delta\left(\alpha_{m}, \beta\right)>0$ and $\Delta_{\alpha}\left(\alpha_{m}, \beta\right)>0$ (which derives from a simple revealed preference argument) imply the existence of a cut-off $\alpha_{l}(\beta)<\alpha_{m}$ such that $\Delta\left(\alpha_{l}, \beta\right)=0$ and $\Delta_{\alpha}\left(\alpha_{l}, \beta\right)>0$. We can have two alternative cases. In the first case, we have $g_{m}[1+\beta(N-1)]>y$ and the function $\Delta(\alpha, \beta)$ is always positive, increasing and with slope approaching a constant for $\alpha \rightarrow H_{g}(y)^{-1}$ and equal to this constant there on. Hence, $\Delta(\alpha, \beta)>0$ for any $\alpha \in\left(\alpha_{l}, \infty\right)$. If instead the 
median country of the union has a low enough $\alpha_{m}$ so that $g_{m}[1+\beta(N-1)] \leq y$, it follows that $\Delta_{\alpha}(\alpha, \beta)$ equals a negative constant for $\alpha \geq H_{g}(y)^{-1}$, which implies that $\Delta(\alpha, \beta)<0$ for $\alpha$ high enough. It follows the existence of a unique value $\hat{\alpha}>\alpha_{m}$, defined by $H\left\{g_{m}[1+\beta(N-1)]\right\}=H\left(g^{o}(\hat{\alpha})\right)$ such that $\Delta_{\alpha}\left(\alpha_{i}, \beta\right) \gtreqless 0$ if and only if $\alpha \lesseqgtr \hat{\alpha}$. This and the concavity of $\Delta(\cdot)$ imply that there must exist an other cut-off $\alpha_{u}(\beta)>\alpha_{m}$ such that $\Delta\left(\alpha_{u}, \beta\right)=0$ and $\Delta_{\alpha}\left(\alpha_{u}, \beta\right)<0$. Hence $\Delta\left(\alpha_{i}, \beta\right)>0$ for any $\alpha_{i} \in\left(\alpha_{l}, \alpha_{u}\right)$. Q.E.D.

LEMMA 2. When a country $k$ outside a union enters in it, utility from staying in the union is increased for the new member $k$ and for any country $i$ on the same side of the median $m$ as the new member, and when two countries on opposite sides of the union enter in it, all countries are better off.

We need to show that, for any $i \leq m$ when $k \leq m$, and for any $i \geq m$ when $k \geq m$ we have $V_{i}^{i n}\left(\alpha^{\prime}\left(\alpha_{k}, \alpha_{m}, N\right), N+1\right)>V_{i}^{i n}\left(\alpha_{m}, N\right)$. The effects induced by entry are to move the median of the union towards the entrant, and to increase the number of members, which has an ambiguous effect on the union policy. However, to prove the claim it is sufficient to show that both effects are going in the right direction. Let us consider the effect of a change in the number of countries for a given median. Using (4) and its comparative statics properties in Proposition 1, we have:

$$
\frac{\partial V_{i}^{i n}\left(\alpha_{m}, N\right)}{\partial N}=\frac{\beta g_{m}\left(\alpha_{m}, N\right)}{[1+\beta(N-1)]}\left[1-\left(\frac{\alpha_{i}-\alpha_{m}}{\alpha_{i}}\right)\left(1-\frac{1}{\theta(\cdot)}\right)\right] \frac{\alpha_{i}}{\alpha_{m}}
$$

which is positive if there is not too much heterogeneity and the $H(\cdot)$ is concave enough. Our assumptions are sufficient conditions for this (indeed, the assumption $\alpha_{\max }<$ $2 \alpha_{\text {min }}$ amounts to an upper bound on the heterogeneity of the preferences since it can be rewritten as $\alpha_{\max }-\alpha_{\min }<\alpha_{\min }$ ). This also shows that when two countries on opposite sides of the median enter the union, this shows that all countries are better off. Let us finally consider the effect of a change in the median for a given number of countries:

$$
\frac{\partial V_{i}^{i n}\left(\alpha_{m}, N\right)}{\partial \alpha_{m}}=\left(\frac{\alpha_{i}-\alpha_{m}}{\alpha_{m}}\right) \frac{g_{m}\left(\alpha_{m}, N\right)}{\alpha_{m} \theta(\cdot)}
$$


where we used (4) and its comparative statics properties in the second line. But $\alpha^{\prime}\left(\alpha_{k}, \alpha_{m}, N\right) \lesseqgtr \alpha_{m}$ if and only if $\alpha_{i} \lesseqgtr \alpha_{m}$, hence the sign of $\left(\alpha^{\prime}\left(\alpha_{i}, \alpha_{m}, N\right)-\right.$ $\left.\alpha_{m}\right)\left[\partial V_{i}^{i n}\left(\alpha_{m}, N\right) / \partial \alpha_{m}\right]$ is the same of $\left[\alpha_{i}-\alpha_{m}\right]^{2}$. Q.E.D.

Proof of Proposition 2. First notice that for a given median there can be only one equilibrium union: if there were more, some countries would be better off in the largest one, hence they could form a coalition and profitably enter in any of the smaller unions, contraddicting their coalition-proofness. ${ }^{22}$ Now, consider the case of Lemma 1 in which $g_{m}[1+\beta(N-1)] \leq y$ and $\alpha_{l}(\beta)$ and $\alpha_{u}(\beta)$ are defined as the preferences for which the utility from staying in a union $\left(\alpha_{m}, N\right)$ is the same as the utility from staying out of it. First we will show that these values are the lower and upper bounds such that all and only all the countries $i \in(l, u)$ belong to the equilibrium union and then we will show that $\partial \alpha_{l}(\beta) / \partial \beta<0$ and $\partial \alpha_{u}(\beta) / \partial \beta>0$. The proof is analogous when $g_{m}[1+\beta(N-1)]>y$. Suppose that a country $k \in(l, u)$ does not belong to the equilibrium union. Notice that from Lemma $2 V_{k}^{i n}\left(\alpha^{\prime}\left(\alpha_{k}, \alpha_{m}, N\right), N+1\right) \geq V_{k}^{i n}\left(\alpha_{m}, N\right)$. Because of this and the fact that $\Delta\left(\alpha_{k}, \beta\right)>0$, it follows:

$$
V_{k}^{\text {in }}\left(\alpha^{\prime}\left(\alpha_{k}, \alpha_{m}, N\right), N+1\right)-V_{k}^{\text {out }}>V_{k}^{\text {in }}\left(\alpha_{m}, N\right)-V_{k}^{\text {out }}=\Delta\left(\alpha_{k}, \beta\right)>0
$$

This contradicts the fact that $\left(\alpha_{m}, N\right)^{E}$ was an equilibrium union. Now suppose that a country $k \notin(l, u)$ belongs to the equilibrium union. Since $\Delta\left(\alpha_{k}, \beta\right) \leq 0$ by construction, it is clearly better for the country to stay out. Again, this contradicts the fact that $\left(\alpha_{m}, N\right)^{E}$ was an equilibrium union. The cut-offs $\alpha_{l}(\beta)$ and $\alpha_{u}(\beta)$ are defined in Lemma 1 by the function:

$$
\left[H\left[g_{m}\left(\alpha_{m}, N\right)(1+\beta(N-1)]-H\left(g^{o}(\alpha)\right)\right]=\frac{g_{m}\left(\alpha_{m}, N\right)-g^{o}(\alpha)}{\alpha}\right.
$$

\footnotetext{
${ }^{22}$ Between the Nash equilibria with a given median, the unique coalition proof equilibrium is the largest one (see AAE, 2001a). This result depends on the high degree of sustituibility between national public goods. In the opposite and extreme case of perfect complements there would not even be a union in equilibrium. We are grateful to a referee for pointing this out.
} 
Total differentiation with respect to $\alpha$ and $\beta$ and repeated use of (4) and the optimality conditions of the outsiders provide:

$$
\frac{d \alpha}{d \beta}=-\frac{g_{m}\left(\alpha_{m}, N\right)(N-1) \alpha}{[1+\beta(N-1)] \Delta_{\alpha}(\alpha, \beta) \alpha_{m}}\left[1-\left(\frac{\alpha-\alpha_{m}}{\alpha}\right)\left(1-\frac{1}{\theta(\cdot)}\right)\right]
$$

whose sign, under our assumptions, is the opposite of the sign of $\Delta_{\alpha}(\alpha, \beta)$ - the proof of this follows the one in Lemma 2. Since $\Delta_{\alpha}\left(\alpha_{l}, \beta\right)>0$ and $\Delta_{\alpha}\left(\alpha_{u}, \beta\right)<0, \alpha_{l}(\beta)$ is decreasing in $\beta$ and $\alpha_{u}(\beta)$ is increasing. Q.E.D.

Proof of Proposition 3. We will prove that an equilibrium union $\left(\alpha_{m}, N\right)^{E}$ accepts any new member $k$ if and only if $\left|\alpha^{\prime}\left(\alpha_{k}, \alpha_{m}, N\right)-\alpha_{m}\right|<\bar{\epsilon}$ for some $\bar{\epsilon}>0$. Define $\epsilon \equiv \alpha^{\prime}\left(\alpha_{k}, \alpha_{m}, N\right)-\alpha_{m}$ and assume that $\alpha_{k}>\alpha_{m}$ so that $\epsilon>0$ (the argument is symmetric in the opposite case). Country 1 will not exit from the union after entry of country $k$ if and only if $V_{1}^{\text {in }}\left[\alpha^{\prime}\left(\alpha_{k}, \alpha_{1}, N\right), N+1\right]>V_{1}^{\text {out }}$. If this condition does not always hold, that is if $V_{1}^{\text {in }}\left[\alpha_{N}, N+1\right]<V_{1}^{\text {out }}$, it holds if and only if $\epsilon$ is lower than a cut-off $\hat{\epsilon}$ defined by:

$$
\left[H\left[g_{m}\left(\alpha_{m}+\hat{\epsilon}, N+1\right)(1+\beta N)\right]-H\left(g^{o}\left(\alpha_{1}\right)\right)\right]=\frac{g_{m}\left(\alpha_{m}+\hat{\epsilon}, N+1\right)-g^{o}\left(\alpha_{1}\right)}{\alpha_{1}}
$$

Now consider the median country $m$. This country will support $k$ 's admission if and only if $V_{m}^{i n}\left[\alpha^{\prime}\left(\alpha_{k}, \alpha_{m}, N\right), N+1\right]>V_{m}^{i n}\left(\alpha_{m}, N\right)$. If this condition does not always hold, that is if $V_{m}^{i n}\left[\alpha_{m+1}, N+1\right]<V_{m}^{i n}\left[\alpha_{m}, N\right]$, it holds if and only if $\epsilon \in\left[\alpha_{m+1}-\alpha_{m}\right]$ is lower than a cut-off $\tilde{\epsilon}$ such that:

$$
\begin{gathered}
{\left[H\left[g_{m}\left(\alpha_{m}+\tilde{\epsilon}, N+1\right)(1+\beta N)\right]-H\left\{g_{m}\left(\alpha_{m}, N\right)[1+\beta(N-1)]\right\}\right]=} \\
=\alpha_{m}^{-1}\left[g_{m}\left(\alpha_{m}+\tilde{\epsilon}, N+1\right)-g_{m}\left(\alpha_{m}, N\right)\right]
\end{gathered}
$$

The claim follows setting $\bar{\epsilon}=\min (\hat{\epsilon}, \tilde{\epsilon})$. Q.E.D.

Proof of Proposition 4. Separability in the subutilities of the public goods implies that in a union $\left(\alpha_{m}, N, G\right)$ the net gain for a country with preferences $\alpha_{i}$ is:

$$
\Pi\left(\alpha_{i}, G\right)=\sum_{k \in G} \Delta\left(\alpha_{i}, \beta_{k}\right)
$$


which defines a continuous function in $\alpha$. By Lemma 1 we know that $\Delta\left(\alpha, \beta_{k}\right)>0$ for any $\alpha \in A_{k}$ where $A_{k}$ is a set such that $A_{F} \subset A_{F-1} \subset \cdots \subset A_{1}$. With an abuse of notation, let us denote with $K$ the set $\{\emptyset, 1,2, \cdots, k\} \subseteq Z_{+}$. Hence, by the properties of a vertical sum of functions, $\Pi\left(\alpha_{i}, G\right)>0$ for any $\alpha \in S_{k}$ where $S_{F} \subset S_{F-1} \subset \cdots \subset S_{1}$. Moreover, $\Pi\left(\alpha_{i}, K+1\right)>\Pi\left(\alpha_{i}, K\right)$ for any $\alpha \in S_{k}$ and $\Pi\left(\alpha_{i}, K+1\right)<\Pi\left(\alpha_{i}, K\right)$ for any $\alpha \notin S_{k}$. In any sub-game perfect equilibrium it must be $\Pi\left(\alpha_{i}, G\right)>0$ for each country $i$ joining the union.

In any union, sequential voting on public good provision implies that the median voter theorem holds for any policy and independently from the order in which policies are voted on. Under rule A, once the union is created, the median country is going to choose its favourite provision of each public good and $G=F$ : hence, for a given median the equilibrium always exists and it is unique (it may be degenerate and include just one country). Under rule B, the same choice of the median country emerges for each policy which is centralised. Let us now consider the stage in which member countries vote on which policy to centralize. Since $\Delta_{\beta}(\alpha, \beta)>0$, it must be that whenever a country wants (not) to centralise policy $z$, the same country wants (not) to centralise any policy $k<(>) z$ : hence we can reduce the set of choice to the set of possible numbers of centralised policies $K \subseteq F$ (taking as given that if $K$ policies are centralised, these are the $K$ policies with highest spillovers). To apply the median voter theorem to this unidimensional set we need to verify single-peakedness: this holds because each country $i$ has a single prefered set of centralized choices $K_{i}$ with $1 \subseteq K_{1} \subseteq K_{2} \cdots \subseteq K_{m-1} \subseteq K_{m}=F$ and $1 \subseteq K_{N} \subseteq K_{N-1} \cdots \subseteq K_{m+1} \subseteq$ $K_{m}=F$. Consequently, under rule B, a set of policies $F \subseteq G$ is centralized. Also under rule $\mathrm{B}$, for a given median, the equilibrium exists and it is unique, but the reason is different and it depends on its coalition proofness. Imagine that there are two equilibria: $\left(\alpha_{m}, N, F\right)^{E}$ and $\left(\alpha_{m}, N^{\prime}, F^{\prime}\right)^{E}$. Our discussion implies a negative correlation between membership and set of centralized policies: if $N>N^{\prime}$ then $F \subset F^{\prime}$ and viceversa. In this case it must be that the countries excluded by the smallest equilibrium could form a coalition and be better off joining the smallest 
union, which contraddicts its equilibrium properties.

Finally in equilibrium under rule B it must be that $\Pi(\alpha, G)>\Pi(\alpha, F)$ for a majority of countries, otherwise a greater set of centralized policies would have been chosen in equilibrium. For more discussion and examples see AAE (2001a). Q.E.D.

Proof of Proposition 5. The first part of the proof is in the text. Now, consider the difference between utility from the equilibria under a complementary union and under a rigid union:

$$
\begin{aligned}
\Omega\left(\alpha_{i}\right) \equiv & \alpha_{i} H\left[g_{i}^{n}+\beta \sum_{j \neq i} g_{j}^{n}+g_{m}^{U}[1+\beta(N-1)]+\right. \\
& -\alpha_{i} H_{g}\left\{g_{m}\left(\alpha_{m}, N\right)[1+\beta(N-1)]\right\}+g_{m}\left(\alpha_{m}, N\right)-g_{i}^{n}-g_{m}^{U}
\end{aligned}
$$

which is a continuous function of $\alpha_{i}$ for given all $\alpha_{j}$ with $j \neq i$. Comparing equilibrium conditions (4) and (11), it follows that $\beta \sum_{j \neq i} g_{j}^{n}+g_{m}^{U}[1+\beta(N-1)]=g_{m}[1+$ $\beta(N-1)]$. Hence, for all countries $i \leq m$ and the other countries for which $g_{i}^{n}=0$, it must be $\Omega\left(\alpha_{i}\right)=g_{m}-g_{m}^{U}>0$ and $\Omega^{\prime}\left(\alpha_{i}\right)=0$. Now, let us consider the countries for which $g_{i}^{n}>0$. In this case, making use of (12) we have:

$$
\begin{aligned}
\Omega^{\prime}\left(\alpha_{i}\right)= & H\left[g_{i}^{n}+\beta \sum_{j \neq i} g_{j}^{n}+g_{m}^{U}[1+\beta(N-1)]\right]-H\left\{g_{m}[1+\beta(N-1)]\right\}+ \\
& +\frac{\beta}{1-\beta} \frac{\partial\left[g_{i}^{n}+\beta \sum_{j \neq i} g_{j}^{n}\right]}{\partial \alpha_{i}}
\end{aligned}
$$

whose last term can be easily verified to be positive. Moreover, since $g_{i}^{n}+\beta \sum_{j \neq i} g_{j}^{n}+$ $g_{m}^{U}[1+\beta(N-1)]>\beta \sum g_{j}^{n}+g_{m}^{U}[1+\beta(N-1)]=g_{m}[1+\beta(N-1)]$, iit follows that $\Omega^{\prime}\left(\alpha_{i}\right)>0$, and hence, every country is better off under the complementary union. Since the net gain function unambiguously moves upward, the set of preferences for which it is better to join the union expands. Hence the equilibrium union can only enlarge after the adoption of a complementary structure. Q.E.D.

Proof Of Proposition 6. Let us consider the case of federal mandates, in which the union moves first. The median country chooses $g_{m}^{U}\left\{\alpha_{m}, E\left[\sum_{j \neq m} g_{j}^{n}\right]\right\}$, 
where $E\left[\sum_{j \neq m} g_{j}^{n}\right]$ is the expectation of the sum of the individual expenditures of all the countries, to maximize $U_{m}$. Then, all the countries choose $g_{i}^{n}, i=1,2, \ldots, N$, to maximize $U_{i}$. In equilibrium it must be $E\left[\sum_{j \neq m} g_{j}^{n}\right]=\sum_{j \neq m} g_{j}^{n}$. Given this, the equilibrium is defined by the following (differential) system of $N+1$ equations: $^{23}$

$$
\begin{gathered}
\alpha_{i} H_{g}\left[g_{i}^{n}+\beta \sum_{j \neq i} g_{j}^{n}+g_{m}^{U}[1+\beta(N-1)]\right] \leq 1, g_{i}^{n} \geq 0 \quad i=1,2, \ldots, N \\
\alpha_{m} H_{g}\left[g_{m}^{n}+\beta \sum_{j \neq m} g_{j}^{n}+g_{m}^{U}[1+\beta(N-1)]\right]=\frac{1}{[1+\beta(N-1)]+\beta \sum_{j \neq m} \frac{\partial g_{j}^{n}}{\partial g_{m}^{\dagger}}}
\end{gathered}
$$

Notice that for a given $g_{m}^{U}$, the first $N$ equations define $g_{i}^{n}=g^{n}\left(\alpha_{i}, g_{m}^{U}\right)$ as functions increasing in the first argument and decreasing in the second one when positive. Hence $[1+\beta(N-1)]+\beta \sum_{j \neq m} \frac{\partial g_{j}^{n}}{\partial g_{m}^{U}} \in(1,1+\beta(N-1)] \cdot{ }^{24}$ This implies 1$)$ that $g_{m}^{U}\left(\alpha_{m}, \sum_{j \neq m} g_{j}^{n}\right) \leq g_{m}^{U}\left(\alpha_{m}, 0\right)$, and that 2$) \alpha_{i} H_{g}(\cdot)<1$ for any $i \leq m$. Finally, 3) positive individual provision is chosen by all countries to the right of the cut-off $\alpha_{b}$ defined by: ${ }^{25}$

$$
\alpha_{b} H_{g}\left[\beta \sum_{j>b} g_{j}^{n}+g_{m}^{U}[1+\beta(N-1)]\right]=1
$$

Now, by totally differentiating the equilibrium first order condition for the individual contributions, we obtain:

$$
\frac{d g_{i}^{n}}{d g_{m}^{U}}=-[1+\beta(N-1)]-\beta \sum_{j>b, j \neq i} \frac{d g_{j}^{n}}{d g_{m}^{U}}
$$

Subtracting from both sides $\beta \frac{d g_{i}^{n}}{d g_{m}^{O}}$ and summing over all $j>b$ we get:

$$
\sum_{j>b} \frac{d g_{j}^{n}}{d g_{m}^{U}}=-\tilde{N}\left\{\frac{[1+\beta(N-1)]+\sum_{j>b} \frac{d g_{j}^{n}}{d g_{m}^{U}}}{1-\beta}\right\}=-\frac{\tilde{N}[1+\beta(N-1)]}{[1+\beta(\tilde{N}-1)]}
$$

\footnotetext{
${ }^{23}$ In this case, it can be verified that single-peakedness always holds in the first stage.

${ }^{24}$ We are implicitly assuming that $g_{m}^{U}>0$. otherwise we would be back at the decentralized equilibrium.
}

${ }^{25}$ Obviously, if $\alpha_{b}>\alpha_{N}$, we are back to the equilibrium with a rigid union. 
where $\tilde{N}$ is the number of countries with $\alpha_{j}>\alpha_{b}$, that is the number of countries providing individual public expenditure, as previously determined. Finally, substituting in the equilibrium condition for the federal choice of the median country (14) follows. Hence, in this case, comparing (14) with (4) we conclude that $g_{m}^{U}[1+\beta(N-1)]<\beta \sum_{j>b} g_{j}^{n}+g_{m}^{U}[1+\beta(N-1)]<g_{m}[1+\beta(N-1)]$ that is $g_{m}^{U}<g_{m}$.

To prove the last part of the Proposition, consider the difference between utility from the equilibria under a federal mandate union and under a rigid union for a given median:

$$
\begin{aligned}
\Psi\left(\alpha_{i}\right) \equiv & \alpha_{i} H\left[g_{i}^{n}\left(\alpha_{i}\right)+\beta \sum_{j \neq i} g_{j}^{n}+g_{m}^{U}[1+\beta(N-1)]\right]+ \\
& -\alpha_{i} H_{g}\left\{g_{m}\left(\alpha_{m}, N\right)[1+\beta(N-1)]\right\}+g_{m}\left(\alpha_{m}, N\right)-g_{i}^{n}\left(\alpha_{i}\right)-g_{m}^{U}
\end{aligned}
$$

which is a continuous function of $\alpha_{i}$ for given all $\alpha_{j}$ with $j \neq i$. By revealed preference, it must be $\Psi\left(\alpha_{m}\right) \geq 0$ with strict inequality if $\tilde{N} \geq 1$. Clearly, we have $\Psi\left(\alpha_{i}\right)=$ $\Psi\left(\alpha_{m}\right) \geq 0$ for any country with $g_{i}^{n}=0$. For $\alpha_{i}>\alpha_{b}$, using (13) we obtain:

$\Psi^{\prime}\left(\alpha_{i}\right)=H\left[g_{i}^{n}\left(\alpha_{i}\right)+\beta \sum_{j \neq i} g_{j}^{n}+g_{m}^{U}[1+\beta(N-1)]\right]-H\left\{g_{m}\left(\alpha_{m}, N\right)[1+\beta(N-1)]\right\}$ which is a convex $\mathrm{U}$ curve (since $\Psi^{\prime \prime}\left(\alpha_{i}\right)>0$ ) reaching a global minimum at $\hat{\alpha}$ such that $\Psi^{\prime}(\hat{\alpha})=0$. However,

$$
\Psi(\hat{\alpha})=g_{m}\left(\alpha_{m}, N\right)-g_{m}^{U}-g_{i}^{n}(\hat{\alpha})=\frac{\beta}{1-\beta}\left[\sum_{j>b} g_{j}^{n}+N g_{m}^{U}-N g_{m}\right]
$$

where we used the definition of $\hat{\alpha}$. Hence, a sufficient condition for every country being better off by adopting a federal mandate system is that this increases total spending. Under this condition, the net gain function unambiguously moves upward and the set of preferences for which it is better to join the union expands. Hence the equilibrium union can only enlarge after the adoption of a federal mandate system. Q.E.D

Proof of Proposition 7. First we prove that the first best can be achieved with the susbsidy $s^{*}=\beta(N-1)$. Let us rewrite (3) as 


$$
\alpha_{i} H_{g}\left(g_{i}^{*}+\beta \sum_{j \neq i} g_{j}^{*}\right)=\frac{1-\beta \sum_{j=1}^{N} \alpha_{j} H_{g}\left(g_{j}^{*}+\beta \sum_{k \neq j} g_{k}^{*}\right)}{(1-\beta)}
$$

and sum over all $i$ 's, we obtain:

$$
\begin{aligned}
\sum_{j=1}^{N} \alpha_{i} H_{g}\left(g_{i}^{*}+\beta \sum_{j \neq i} g_{j}^{*}\right) & =N\left[\frac{1-\beta \sum_{j=1}^{N} \alpha_{j} H_{g}\left(g_{j}^{*}+\beta \sum_{k \neq j} g_{k}^{*}\right)}{(1-\beta)}\right]= \\
& =\left(1+\frac{\beta N}{1-\beta}\right)^{-1}\left(\frac{N}{1-\beta}\right)=\frac{N}{1+\beta(N-1)}
\end{aligned}
$$

Substituting in the previous equation we obtain the equivalent expression:

$$
\alpha_{i} H_{g}\left(g_{i}^{*}+\beta \sum_{j \neq i} g_{j}^{*}\right)=\frac{1-\beta \frac{N}{1+\beta(N-1)}}{(1-\beta)}=\frac{1}{1+\beta(N-1)}
$$

Clearly the proposed optimal subsidy is such that the equilibrium first order conditions and the first best ones have the same solutions $g_{i}[1+\beta(N-1)]=g_{i}^{*}$ for $i=1, \ldots, N$. Second, public spending maximizing (15) satisfies:

$\alpha_{i} H_{g}\left\{(1+s)\left[g_{i}+\beta \sum_{j \neq i} g_{j}\right]\right\}(1+s)=1$ with $g_{i}^{\prime}(s)=\frac{g_{i}+\beta \sum_{j \neq i} g_{j}}{(1+s)}\left(\frac{1-\theta_{i}(s)}{\theta_{i}(s)}\right)$

where $\theta_{i}(s) \equiv \theta\left[g_{i}(s)+\beta \sum_{j \neq i} g_{j}(s)\right]$. Using the envelope condition, the subsidy maximizing (16) for the median country must satisfy the first order condition (17) the second order condition is assumed satisfied - which, using $g_{i}^{\prime}\left(s_{m}\right)$, can be rewritten as:

$$
\left[\frac{g_{m}\left(s_{m}\right)}{\bar{g}_{-m}}+s^{*}-1-s_{m}\right]=\left[\frac{s_{m}}{N-1}-\beta\right] \sum_{j \neq i} \frac{1-\theta_{j}\left(s_{m}\right)}{\theta_{j}\left(s_{m}\right)}\left(g_{j}\left(s_{m}\right)+\beta \sum_{k \neq m} g_{k}\left(s_{m}\right)\right)
$$

Notice that single-peakedness of preferences requires $\partial^{2} V_{i} / \partial s \partial \alpha_{i}>0$, which holds under weak conditions and is assumed here. In conclusion it is immediate to verify that when $g_{m}\left(s_{m}\right)=\bar{g}_{-m}$ it must be $s_{m}=s^{*}$. The tax system implies that $T_{i}$ is decreasing in $\alpha_{i}$. If this makes some countries with low preference for public spending worse off compared to be outside the union, quasilinearity implies that there is always a transfer which does not affect the allocation of public spending but makes those countries better off. Q.E.D. 